\title{
Symposium
}

\section{Assessing Bettors' Ability to Process Dynamic Information: Policy Implications}

\author{
Johnnie E. V. Johnson,* Raymond O’Brien, $†$ and Ming-Chien Sung $\nleftarrow$
}

\begin{abstract}
Regulation is often employed to encourage the provision of readily interpretable, explicit information to betting markets in an effort to promote their efficiency. This approach is supported by a considerable volume of laboratory-based research which suggests that individuals make poor judgments in the face of implicit, dynamic information. This article investigates to what extent horserace bettors, who have strong incentives to make good probability judgments, require the regulator's protection from such hostile information environments. In particular, we examine the accuracy of the subjective probabilities of bettors concerning 16,344 horses in 1671 races. We find that bettors are skilled in adopting effective heuristics to simplify their dynamic information environment and, even in the face of restricted information, develop well-calibrated judgments using outcome feedback. A number of factors that help bettors to achieve good calibration are identified and the implications for market regulation are discussed.
\end{abstract}

JEL Classification: G13, G14, G17

\section{Introduction}

Success in many areas of human endeavor stems from the ability to convert rapidly changing information into accurate probability judgments. Dynamic information environments are often subject to sporadic adjustments resulting from structural instabilities (e.g., in the business world, from announcements concerning impending acquisitions or innovations). There is a wealth of laboratory-based evidence that individuals base their forecasts on human judgment rather than statistical methods when faced by such dynamic information (e.g., Dalrymple 1987; Taranto 1989). These forecasts are often based on heuristics, which result in systematically biased judgments (Kahneman et al. 1982; Timmermans 1993; Baranski and Petrusic 1995). These problems are exacerbated if the information remains implicit (e.g., rumor). Consequently, in an effort to counteract the adverse impact these effects might have on market efficiency, regulators attempt to ensure that market participants receive information in a timely, explicit, and consistent fashion. While the need for information to promote market

\footnotetext{
* Centre for Risk Research, School of Management, University of Southampton, Highfield, Southampton, SO17 1BJ, United Kingdom.

$\uparrow$ School of Social Sciences, Economics Division, University of Southampton, Highfield, Southampton, SO17 1BJ, United Kingdom.

\$ Centre for Risk Research, School of Management, University of Southampton, Highfield, Southampton, SO17 1BJ, United Kingdom; E-mail m.sung@soton.ac.uk; corresponding author.

The authors wish to thank the anonymous referees and the editors of the special issue for their valuable comments on an earlier draft of this article.
} 
efficiency is not under dispute, there is growing evidence that individuals may not require explicit information. For example, Remus et al. (1996, p. 23) indicate that "humans have the ability to detect and react to structural instability that characterizes many business forecasting tasks" and there is evidence that judgmental forecasters can develop well-calibrated subjective probability judgments under appropriate conditions (e.g., Johnson and Bruce 2001).

In summary, there are conflicting views concerning decision makers' ability to handle structurally unstable, implicit information. However, much of the evidence that questions the reliability of individuals' probability judgments has been derived from the laboratory. Consequently, this article examines to what extent and in what manner individuals' probability judgments in a real-world betting market account for dynamic, often implicit, information. The aim is to provide betting market regulators with evidence to help them decide which information is necessary to promote market efficiency and how it needs to be disseminated. This may help avoid the pitfalls of an over-regulated, stifled market whilst allowing for an adequate flow of appropriate information.

The remainder of the article is organized as follows. Section 2 reviews the literature addressing probability judgments in dynamic information environments and outlines the article's research questions. Section 3 describes the data, explains the methodological advantages of the chosen setting, and describes the procedures used to explore the research questions. Section 4 presents the results, which are discussed in section 5. Some concluding remarks follow in section 6 .

\section{Probability Judgments in Dynamic Environments}

\section{Existing Literature}

Complexity exacerbates the difficult task of processing data and increases when the information required for judgments remains uncertain and changes through time. Under such conditions, individuals often rely on their own judgments rather than on statistical forecasts (e.g., Kleinmutz 1990; Sanders and Manrodt 1994). These judgments are often less accurate than forecasts based on simple statistical models (e.g., Mocan and Azad 1995; Remus et al. 1995) because the latter forecasts act as a form of task information feedback, which can improve judgments even more than outcome feedback (Balzer et al. 1994; Remus et al. 1996; Sanders, 1997).

Individuals' assessment of dynamic information can be hindered by their limited cognitive capacity (Hogarth 1987). This capacity is challenged by increased complexity, arising, for example, from implicit information. Under such conditions individuals increasingly rely on heuristics (Bolger and Harvey 1993), which can result in systematic biases (Kahneman et al. 1982; Fildes 1991; Cohen 1993; Harvey et al. 1994) and a reduction in decision quality (Malhotra 1982; Ford et al. 1989; Timmermans 1993) and probability judgment accuracy (Baranski and Petrusic 1994, 1995; Suantek et al. 1996). Furthermore, poor calibration is exacerbated if the information is uncertain or changing (Griffin and Tversky 1992; Chinander and Schweitzer 2003). The assessment of dynamic information is also hindered by the tendency to desire consistent information (Soll 1999). This leads to dissonant information being discounted (Harries et al. 2004), which reduces the ability to react to structural shifts. 
From the previous discussion it is clear that there are a number of factors that can reduce an individual's ability to effectively handle dynamic information. However, research suggests that these findings may arise from the artificial nature of some experimental calibration studies (Gigerenzer et al. 1991; Ayton and Wright 1994). The excellent calibration observed in some naturalistic settings appears to support this view (Murphy and Brown 1985; Keren 1991; Johnson and Bruce 2001). There is also evidence that certain factors can support probability judgments under dynamic, naturalistic information conditions. For example, individuals alter behavior based on outcome information (Kopelman 1986; Jones et al. 1997) and they tend to make judgments based on the most recent evidence in a sequence of contradictory evidence (Ashton and Kennedy 2002). "Recency" may foster appropriate reaction to structural shifts in an evolving information set. In addition, it has been proposed that evolution has equipped individuals to process probabilistic information from frequencies observed in a natural environment (Gigerenzer 2000; Hoffrage et al. 2002). In summary, there is mixed evidence concerning individuals' ability to handle dynamic information.

Can individuals make full use of dynamic information even if this is not made explicit? The answer to this question may affect how policy makers frame their regulations concerning the provision of information to market participants.

\section{Regulation Policy and Research Questions}

The British Horseracing Authority (BHA), the official regulatory authority governing U.K. horse racing, administers the rules of racing. For example, they ensure that racetracks adhere to a set of common standards, including the minimum levels of information they must provide to the betting public (e.g., explanations required of trainers if their horses perform unexpectedly badly, etc.). The BHA is mindful of the need to develop regulations that ensure the sport is run effectively and efficiently and in the best interests of a range of stakeholders (e.g., racehorse and racetrack owners, and the betting public). This is achieved by maintaining a balance between sufficient and overly restrictive regulation (which may stifle or reduce the attraction of the sport and the betting market on which it depends).

Racetrack operators can cause structural shifts in the information provided to bettors (which they require to make accurate probability judgments). For example, racetrack operators can alter the ground conditions between races (e.g., through harrowing or rolling tracks with artificial surfaces). This could, for example, change the advantage of a particular post position (hereafter PP: the barrier position from which a horse starts a race). Previous laboratory-based research, discussed above, suggests that bettors are unlikely to make good probability judgments in the face of such structural shifts, particularly if the information remains implicit or is only allowed to leak out in the form of rumor. If regulators believe that bettors will not effectively process implicit, dynamic information created by such management changes, they might require racetrack operators to minimize the degree to which they engage in these practices and/or to announce their actions in advance. Consequently, to assist the regulators in making such judgments, two key research questions are addressed: To what extent bettors, when faced by a dynamic and implicit information set, (i) account for the full information content of evolving data in their probability judgments, and (ii) form good probability judgments based on heuristics that employ a linear model of current information or a historical model that accounts for the full complexity of information from previous trading periods. 


\section{Methodology}

This section explains why the horserace betting market is an ideal setting for studying the manner in which dynamic information is used in forming probability judgments and introduces the dataset and procedures that will be used to address the research questions.

\section{Characteristics of the U.K. Horserace Betting Markets}

In discussing the characteristics of the U.K. horserace bookmaker betting market, the following topics will be addressed: (i) the manner in which subjective probability judgments are revealed in betting markets, (ii) the similarities between decisions made in betting markets and those made in other environments, (iii) how the availability of an unequivocal outcome to a horserace facilitates the analysis of the manner in which information is used by bettors, and (iv) the nature of the particular dynamic information set that is used in this study.

\section{Revelation of Probability Judgments in Betting Markets}

Bettors in U.K. bookmaker horserace betting markets purchase assets (place bets), the returns to which depend upon the result of the horserace to which the particular market relates. "In its simplest formulation, the market for bets in an $n$-horse race corresponds to a market for contingent claims with $n$ states in which the $i$ th state corresponds to the outcome in which the $i$ th horse wins the race" (Shin 1993, p. 1142). The odds of horse $i$ in race $j\left(O_{i j}\right)$ are determined initially by bookmakers' perceptions of the probability of each horse winning. They then adjust the odds as new information becomes available, much of which arrives in the form of bets placed on each horse. Bettors have an incentive to continue to place money on a given horse until its odds are proportional to the market's best estimate of that horse's chance of winning the race (Figlewski 1979). In state-contingent claim terms, the purchase price of a claim on horse $i$ in race $j$ is given by the fraction of one pound denoted by $1 /\left(1+O_{i j}\right)$. This claim will pay one pound if the horse wins but nothing if it loses. Consequently, in line with Figlewski's (1979) argument, we assume that the market's subjective probability is given by

$$
p_{i j}^{s}=\frac{1 /\left(1+O_{i j}\right)}{\sum_{i=1}^{n_{j}} 1 /\left(1+O_{i j}\right)}
$$

where $n_{j}$ is the number of horses in race $j$. In a bookmaker market the final market odds combine the views of those who determine horses' chances of success using some private information (for example, owners, trainers, etc.) and those who use largely publicly available information (i.e., the wider betting public and the bookmakers themselves).

\section{Betting Markets: Similarities to Other Decision Environments}

The appeal of betting markets as settings for empirical enquiry into various aspects of decision making is well-established (Hong and Chiu 1988; Law and Peel 2002; Paton et al. 2009). They share many features in common with wider financial markets (Snyder 1978) and they provide a means of examining decisions made in a natural environment that involves 
multi-events, multi-cues and informational turbulence, the conditions that exist in many naturalistic environments (Orasanu and Connolly 1993).

\section{The Advantages of an Unequivocal Outcome}

Sauer (1998) observes that betting markets offer an opportunity to understand economic behavior that might prove difficult in more complicated financial markets. The main reason for this is that betting markets generate an unequivocal outcome (a winner) within a finite time frame. Consequently, there is a point in time at which all uncertainty in the market is resolved, providing an objective benchmark against which to measure the quality of the probability judgments, revealed as odds. More specifically, the subjective probabilities inherent in odds and associated with particular information features (for example, a horse's PP) can be compared with the objective probability of success (as revealed, ex post, by race outcomes). This provides a basis for assessing the degree to which information (for example, PP) is discounted in odds. In addition, there is a large pool of markets (races) of essentially similar type available for analysis.

\section{The Nature of the Dynamic Information Set}

This article explores the extent to which bettors employ dynamic and often implicit information relating to "PP bias" in their probability judgments. The nature of PP bias information and why this might be regarded as a dynamic information set is now explained.

Horses running in flat races of less than two miles in the United Kingdom are required to begin their races from "starting stalls," which are devices that ensure that all horses are released to start the race at the same moment in time. Each horse is randomly allocated a PP, and these are announced the day before the race. The PP determines where in relation to the inside of the racetrack the horse will start the race and where the horse is often forced, due to the position of other runners, to run much of the race. Due to track configuration (e.g., short oval racetracks with sharp bends) or other racetrack topography (e.g., faster ground on the outside of the track), certain PPs may be advantageous. Most racing publications agree that PP needs to be considered carefully when assessing a horse's chances. For example, Cotton (1990, p. 113), in an influential book on horserace betting, advises "... make no mistake, post-position can be the most important component in the outcome of many flat races." Similarly, Beyer (1983, p. 42) observes: "while most biases are due to the idiosyncrasies in the racing surface, many tracks have shapes that influence the results. At tracks less than a mile in circumference, the sharp turns and short straight almost always work to the advantage of the front runners and horses on the inside."

Data from a U.K. racetrack (Wolverhampton), which has a configuration similar to that referred to by Beyer (1983), is employed in this study. Wolverhampton is a small oval circuit of only one mile circumference with tight bends and a short run in of 380 yards. It is surfaced with "fiber-sand," a mixture of sand bound together loosely by synthetic fibers. Racing commenced there in December 1993, and the dataset for the current study contains races run between 1995 and 2000. Races run earlier than this period were not chosen because bettors had little available evidence on which to base their views of the PP bias and expert advice concerning the bias in racing publications was not available to bettors. Races run after 2000 were not examined 
because major changes occurred in U.K. horserace betting at this time (e.g., the introduction of Betfair). These changes are likely to have significantly changed market ecology and the composition of market participants in such a way as to alter the degree to which data is discounted in odds.

During the period of analysis the racetrack managers engaged in various practices to try to eliminate PP bias. There are a number of reasons why they may have sought to eliminate PP bias, including that the bias may deter owners and trainers of better horses from entering races for fear that their prospects may be unduly influenced by the random PP draw. In addition, jockeys may engage in dangerous riding tactics in an attempt to offset the effects of a poor PP, and bettors, particularly informed bettors, may be deterred if they believe that PP bias unduly complicates the analysis of a horse's prospects.

Wolverhampton's racetrack managers used a variety of measures to eliminate the PP bias, including altering the drainage system, resurfacing the track and changing the harrowing (mechanical raking to prevent compaction of the surface), and watering and "luting" (mechanical raking to distribute sand evenly across the track) practices at different meetings - even after particular races at the same meeting. No record was kept of the precise timing of these track management changes, and the changes concerning harrowing and luting practices were never announced to the public. Although experienced racegoers may have observed some of these practices, the majority of the betting public (who, in the United Kingdom, bet in betting offices away from the racetrack) would not be explicitly aware of these changing practices. They could only discern changing PP bias by their analysis of past results. Interviews with the Clerk of the Course (who has overall responsibility for management of the racetrack) confirmed that he believed that these practices did have a significant effect on the PP bias. The changing nature of comments in racing publications concerning the PP bias at Wolverhampton during this period corroborates his view. These comments range from "high numbers had a marked advantage in the early stages on the new fiber-sand course, but the effect seems to be diminishing" (Raceform, 1995, p. xvi) to "high numbers have a definite advantage" (Superform-Races and Racehorses, 1996, p. 1511) and later "high numbers have the moderate advantage" (Superform-Races and Racehorses, 2000, p. 1716).

In summary, PP data in horserace betting markets is likely to represent a sporadically changing (e.g., when new track management practices are introduced), evolving (jockeys may alter their riding tactics over a period to try to compensate for the bias), and often implicit (e.g., when bettors are not made aware of the changes) information set.

\section{Data and Procedures}

This section describes the data and the procedures employed in this study: First, a model is introduced that is designed to capture the extent to which PP bias influences a horse's chance of success. This is used to evaluate the information content of PP bias. Second, a procedure is outlined that facilitates measurement of the extent to which the information contained in PP bias is accounted for in bettors' probability judgments. Third, we discuss how the model of PP bias is used to confirm that the bias changed. Finally, procedures are introduced for testing the extent to which bettors' probability judgments incorporated simplified models of PP bias based on current year or historical PP bias. 


\section{Data}

The dataset employed in this study contains details of the PP, the final declared odds from the bookmaking market, and the finishing positions for each of 16,344 runners in 1671 races run at Wolverhampton racetrack between January 1995 and August 2000. The races were run over distances from 5 to 16.21 furlongs (1100 to 3566.2 yards), with a mean of 8.46 furlongs (1860.1 yards), the majority of races (1527) being run at distances of less than 12 furlongs (2640 yards). The number of runners in each race varied from 2 ( 1 race) to 13 (254 races), with a mean of 9.8, most races involving more than eight runners (1329 races).

\section{Post-Position Bias Model}

In developing a model to account for Wolverhampton's PP bias, we consulted a number of racing publications that provide statistics and advice to bettors concerning this topic. While there were clear differences from year to year, most agreed that horses with a "high" PP (i.e., starting stalls position furthest from the centre of the track) had an advantage. This advantage is counterintuitive when simply considering the configuration of the Wolverhampton track (a small oval circuit) as horses with low PPs are most likely to run on the inside of the track, reducing the total distance they must run. Discussions with the Clerk of the Course and with horseracing experts from a leading racing publication (Raceform) helped to identify possible physical reasons for the PP bias. The racetrack is cambered, two degrees on the straights and four degrees on the bends, and, consequently, sand can migrate towards the centre of the track, making the ground there soft compared to the relatively firm ground towards the outside of the track, causing horses running nearer the center of the track to run more slowly. The consensus was that loose material migrates to the inside rail during very dry weather and/or cold weather. During very dry weather the lack of moisture in the sand means it easily migrates when kicked up by horses. To prevent the track from freezing in cold conditions it is mechanically deepraked (harrowed) between races and this process can cause loose material to migrate to the inside (this process can occur between race meetings under "normal" weather conditions). In addition, during wet conditions, water drains from the outside towards the inside of the track, carrying loose material to the center of the track. This causes the inside rail area of the track to become more water-logged than that up the slope, again causing horses on the inside to run slower than those running wide on the track. Consequently, whatever the weather conditions, it is generally believed that Wolverhampton racetrack's topology causes the inside rail ("low PP") to have the least favorable underfoot conditions. This disadvantage accrues, despite the shorter distance traveled by a horse on the inside rail and the disadvantage experienced by those running on the outside of having to run up a greater slope on each bend (there is a two-degree difference in gradient between the slope and the bend). Betton (1994, p. 512) estimates that such a climb is likely to cause a $20 \%$ "reduction in horse's pulling ability," without equivalent compensation in muscular energy when running down the slope into the straight. The Clerk of the Course also indicated that in the first few years of running at Wolverhampton harrowing was only performed across $80 \%$ of the racetrack, from the inside rail outwards. Consequently, it is possible that the fiber-sand surface towards the outside became more compacted, resulting in faster underfoot conditions.

In developing a PP bias model, we define the following variables: $b_{j}=$ the number of bends in a particular race $j, r=$ the radius of a bend in yards, $D_{j}=$ the official distance of the race in 
yards (measured around inside rail), $w=$ the average effective width of a racing horse in yards, and $m_{i j}+1=$ horse $i$ 's PP in race $j$. Jockeys may maneuver their horses during a race to occupy positions relative to the inside rail that are different from their initial post positions. However, this can be difficult because moving to the outside rail will involve exertion of energy to move up the camber and moving closer to the rail often requires exertion of energy to get in front of other horses. Consequently, when developing the model it is assumed that horses remain throughout the race in the position relative to the inside of the track determined by their PP. Then the distance traveled around bends by horse $i$ in race $j$ is given by $b_{j} \pi\left(r+m_{i j} w\right)$ and the distance traveled on straights is given by $D_{j}-b_{j} \pi r$. We assume that the average speed of a horse running over a distance of $D$ on the inside rail is $f(D) \mathrm{S}_{1}$, where $\mathrm{S}_{1}=$ the average speed of a horse running on the inside rail over a distance of 1100 yards (the shortest distance race) and $f(D)$ is a function which determines the reduction in average speed of a horse running on the inside rail over a distance of more than 1100 yards (i.e., $f[1100]=1$ ). To simplify the model, it is assumed that horses can run at the same average speed around bends as on the straight. It is also assumed that due to changes in the composition of the track surface, horses run slower/ faster the further they are from the inside rail and that there is a differential effect on straights (cf. around bends) and at different race distances, captured by $g\left(m_{i j}, D_{j}\right)$ and $h\left(m_{i j}, D_{j}\right)$. These functions determine the increase/reduction in average speed of horse $i$ running in PP (i.e., $m_{i j}+$ 1) on straights and bends, respectively, over a distance of more than 1100 yards compared to a horse running on the inside rail over 1100 yards. Consequently, the average speed of a horse drawn $m_{i j}+1$ running on straights at distance $D_{j}$ is $g\left(m_{i j}, D_{j}\right) \cdot f\left(D_{j}\right) \cdot \mathrm{S}_{1}$, and running round bends is $h\left(m_{i j}, D_{j}\right) \cdot f\left(D_{j}\right) \cdot \mathrm{S}_{1}$.

To estimate the form of $f(D)$, curve fit facilities in SPSSX were used to determine the relationship between the published record speeds at each distance at Wolverhampton divided by the record speed at 1100 yards (i.e., $\mathrm{S}_{1}$ ) and the race distance $D$. The relationship appeared to be approximately linear with the following form: $f(D)=1.0317-0.00004 D\left(R^{2}=0.96\right)$.

In estimating the functional forms of $g(m, D)$ and $h(m, D)$, the properties these might be expected to exhibit were considered: They should be capable of giving a number greater than/ less than 1 when the average speed of a horse drawn at position $m+1$ over distance $D$ is faster/ slower than a horse drawn on the inside rail $(m=0)$ in a 1100 yard race, and, in addition, they should allow $g(0,1100)=h(0,1100)=1$. Moreover, it is expected that the effect of differential speed should be most marked near the inside rail (i.e., when $m$ approaches zero) and for the marginal effect to decline as $m$ increases. Consequently, a simple form of these functions might be $g(m, D)=1 /(1+\alpha \sqrt{m})$ and $h(m, D)=1 /(1+\beta \sqrt{m})$. When exploring changes in the PP advantage from year to year, it will be useful to assess to what extent the bias varies with race distance and, consequently, functions of the following form, which have these properties, will then be adopted: $g(m, D)=1 /\left(1+\alpha m^{D / x}\right)$ and $h(m, D)=1 /\left(1+\beta m^{D / y}\right)$ where $\alpha, \beta, x$ and $y$ are to be estimated.

The time it takes for a horse $i$ drawn $m_{i j}+1$, to complete a race $j$ is, therefore, proportional to the distance traveled on straight track divided by its average speed on straight track plus the distance traveled on bends divided by its average speed on bends. This is given, as follows:

$$
\frac{\left(D_{j}-b_{j} \pi r\right)\left(1+\alpha m_{i j}^{D_{j} / x}\right)}{\left(1.0317-0.00004 D_{j}\right) \mathrm{S}_{1}}+\frac{b_{j} \pi\left(r+m_{i j} w\right)\left(1+\beta m_{i j}^{D_{j} / y}\right)}{\left(1.0317-0.00004 D_{j}\right) \mathrm{S}_{1}} .
$$


Clearly, the winner of race $j$ will be the horse with the minimum value of this function, and because $S_{1}$ is a constant, this is equivalent to identifying the horse with the maximum value of the following function:

$$
\frac{-\left(D_{j}+b_{j} \pi m_{i j} w\right)}{\left(1.0317-0.00004 D_{j}\right)}-\frac{\left(D_{j}-b_{j} \pi r\right)\left(\alpha m_{i j}^{D_{j} / x}\right)}{\left(1.0317-0.00004 D_{j}\right)}-\frac{b_{j} \pi\left(r+m_{i j} w\right)\left(\beta m_{i j}^{D_{j} / y}\right)}{\left(1.0317-0.00004 D_{j}\right)} .
$$

Hereafter, the first element in this function will be referred to as the "distance factor," the second element as the "straights factor," and the third element as the "bends factor."

The aim is to use the sample data to estimate the optimal values for $\alpha, \beta, x$, and $y$. To achieve this, a "winningness" index $W_{i j}$ of horse $i$ in race $j$ is defined as function (2) given above $\left(f_{2}(\alpha, \beta, x, y)\right)$, plus an independent error term $\varepsilon_{i j}$ as follows:

$$
W_{i j}=f_{2}(\alpha, \beta, x, y)+\varepsilon_{i j} .
$$

$W_{i j}$ is defined such that the horse that is observed to win a particular race has the largest winningness index of all runners in that race. Consequently, the probability of horse $h$ winning race $j\left(p_{h j}\right)$ is given as follows:

$$
p_{h j}=\operatorname{Pr}\left(W_{h j}>W_{i j}, i=1,2, \ldots . n_{j}, i \neq h\right),
$$

where $n_{j}=$ number of runners in race $j$. Consequently,

$$
p_{h j}=\operatorname{Pr}\left(f_{2}(\alpha, \beta, x, y)_{h j}+\varepsilon_{h j}>f_{2}(\alpha, \beta, x, y)_{i j}+\varepsilon_{i j}, i=1,2 \ldots n_{j}, i \neq h\right) .
$$

The $W_{i j}$ cannot be observed directly. However, whether horse $i$ wins race $j$ can be observed and a win/lose variable $t_{i j}$ is defined such that

$$
t_{i j}=1 \quad \text { if } W_{i j}=\operatorname{Max}\left(W_{1 j}, W_{2 j}, \ldots, W_{n j j}\right) ; \quad t_{i j}=0 \text { otherwise. }
$$

Consequently, the probability of horse $h$ winning race $j$ can be represented as follows:

$$
p_{h j}=\operatorname{Pr}\left(t_{h j}=1 \mid f_{2}(\alpha, \beta, x, y)_{i j}, i=1,2 \ldots . ., n_{j}\right) .
$$

McFadden (1974) demonstrates that if the error terms $\varepsilon_{i j}$ in Equation 5 are assumed to be independent (and this seems likely as PP for each race is allocated by a random device) and distributed according to the double exponential distribution, this produces the conditional logit (CL) function. Consequently, the probability of horse $i$ winning race $j$ is given as follows:

$$
p_{i j}=\frac{\exp \left(f_{2}(\alpha, \beta, x, y)_{i j}\right)}{\sum_{i=1}^{n_{j}} \exp \left(f_{2}(\alpha, \beta, x, y)_{i j}\right)},
$$

where $\alpha$ and $\beta$ are parameters that measure the importance of PP in determining the likelihood of horse $i$ winning race $j$ (for the distance run on straight track and on bends, respectively). The parameters $\alpha, \beta, x$, and $y$ are estimated by maximizing the joint probability of observing the results of all $J$ races in the sample. Consequently, the value of the following 
log-likelihood (LL) function is maximized:

$$
\mathrm{LL}=\sum_{j=1}^{J} \sum_{i=1}^{n_{j}} t_{i j} \ln p_{i j} .
$$

Thus, we assume the outcomes of races are independent events and following McFadden (1974) we assume that the random components $\varepsilon_{h j}$ of the winningness indices for different horses are independent.

\section{Modeling Bettors' Subjective Probability Judgments}

To measure the extent to which bettors use the information content of PP bias in their judgments revealed in the prevailing market odds, two CL functions are estimated. The first incorporates simply the log of the probability implied by the final market odds, $p_{i j}^{s}$ :

$$
p_{i j}=\frac{\exp \left(\lambda \ln \left(p_{i j}^{s}\right)\right)}{\sum_{i=1}^{n_{j}}\left(\lambda \ln \left(p_{i j}^{s}\right)\right)} .
$$

The second incorporates both $p_{i j}^{s}$ and a function similar to that derived above to account for PP bias (i.e., $\left.f_{2}(\alpha, \beta, x, y)\right)$ :

$$
p_{i j}=\frac{\exp \left(f_{2}(\alpha, \beta, x, y)_{i j}+\varphi \ln \left(p_{i j}^{s}\right)\right)}{\sum_{i=1}^{n_{j}} \exp \left(f_{2}(\alpha, \beta, x, y)_{i j}+\varphi \ln \left(p_{i j}^{s}\right)\right)} .
$$

As discussed above, the parameters, $\alpha, \beta, x, y, \varphi$ and $\lambda$ are estimated by maximizing the appropriate likelihood functions.

The maximum likelihood (LL) value of the model represented by Equation 10 is compared with the maximum LL of the model represented by Equation 9 using a likelihood ratio (LR) test. If the test detects a significant difference, this will imply that some of the information concerning PP bias is not accounted for in bettors' decisions.

\section{Modeling the Changing Nature of Post-Position Bias through Time}

In order to confirm that PP bias at Wolverhampton racetrack changes through time, three procedures are employed:

First, for each of the six years (1995-2000), CL models represented by Equation 7 are estimated. The degree to which PP bias explains winning probabilities is then determined using the pseudo- $R^{2}$ (Hauser 1978). Clearly, large differences in $R^{2}$ from year to year would suggest that the degree to which PP affects winning probabilities also changes substantially.

Second, the values of the parameters $\alpha, \beta, x$, and $y$ in the CL models developed for each of the six years are compared. Large differences in the size, sign, and significance of these parameters would suggest that the influence of the different elements of PP bias captured by (2) changes over time (e.g., distances traveled around bends).

Third, the sum of the information content of each of the individual year's models is compared with the information content of a combined model for all six years (1995-2000); the 
information content of each year $k$ 's model being measured by its maximum LL value, $L_{k}$, and the combined model's information content being measured by its maximum LL value, $L_{c}$. If the parameters are time-invariant, the quantity $-2\left(L_{c}-\sum_{k} L_{k}\right)$ is distributed $\chi_{n}^{2}$, where $n$ is the difference between the total number of parameters estimated in the individual year's models and the number of parameters estimated in the combined model. If this LL ratio test is significant, it suggests that if the coefficients of the various parameters are allowed to change from year to year, the separate annual models better explain the PP bias than a combined model for 1995-2000 (Windmeijer 1995).

Finally, in order to explore the extent to which bettors account for the changing PP bias over the period, LR tests, similar to those discussed in "Modeling Bettors' Subjective Probability Judgments" are conducted for each of the years. Significant differences in the LR values of these models in a given year will suggest that bettors do not fully account for PP bias in their betting decisions in that particular year.

\section{Simplified Models of Post-Position Bias}

As will be shown below, bettors do not fully discount all information concerning PP bias. Consequently, we examine the nature of the PP bias information that bettors do take into account when making their betting decisions. In particular, we explore two heuristics or simplified models they may adopt: (i) an historical CL model of PP bias that incorporates probabilities derived from a comprehensive model of PP bias effects from the previous year, $t-$ 1, and (ii) a simple model that accounts for linear PP effects using the current year's data.

When forming subjective probability estimates of a horse's chance of winning, it is conceivable that bettors rely on data concerning PP bias from the previous year. This is the information that appears in annual racing publications designed to aid horse selection. To examine the extent to which individuals incorporate a comprehensive model of PP bias effects from year $t-$ 1 when making their betting decisions in year $t$, the maximum LL values of two alternative CL models are compared. The first simply incorporates odds probabilities (i.e., the model represented by Eqn. 9, estimated using current year $[t]$ data). The second is represented as follows:

$$
p_{i j}=\frac{\exp \left(\tau \ln \left(p_{i j}^{s}\right)+v \ln \left(p_{i j}^{t-1}\right)\right)}{\sum_{i}^{n j}\left(\exp \left(\tau \ln \left(p_{i j}^{s}+v \ln \left(p_{i j}^{t-1}\right)\right)\right)\right)} .
$$

The $p_{i j}^{t-1}$ values are estimated from a CL model incorporating PP bias effects from year $t-1$ as follows:

$$
p_{i j}^{t-1}=\frac{\exp \left(f_{2}(\alpha, \beta, x, y)_{i j}^{t-1}\right)}{\sum_{i=1}^{n_{j}} \exp \left(f_{2}(\alpha, \beta, x, y)_{i j}^{t-1}\right)},
$$

where the parameters $\alpha, \beta, x$, and $y$ are fixed and take the values obtained by estimating the $\mathrm{CL}$ model indicated in Equation 7, estimated using year $t-1$ data. If it can be shown that a model which simply incorporates odds probabilities contains as much information as a model that incorporates odds probabilities and probabilities based on PP bias observed in the previous year, this will then suggest that bettors' subjective judgments, revealed in the odds, fully account for the historical model of PP bias. 
Rather than rely on a historical model of PP bias, bettors may use a simplified (linear) model of current data to capture PP bias effects. In order to explore this possibility, we first established (from the $R^{2}$ statistic) the degree to which the following model (which simply incorporates linear PP bias effects) explains horses' winning probabilities:

$$
p_{i j}=\frac{\exp \left(\delta m_{i j}\right)}{\sum_{i=1}^{n_{j}} \exp \left(\delta m_{i j}\right)} .
$$

To test whether the linear model of PP bias (13) explains variation in winning probabilities of horses as well as the more comprehensive model of PP bias (7), the LL of the two models are compared using an encompassing test (Mizon and Richard 1986) for non-nested models. In this application, we fit the obvious combined model, which includes both the linear (13) and the comprehensive model (7). If the parameters peculiar to (13) are insignificant, one accepts the hypothesis that (7) "encompasses" (13), and vice versa. There are four possible outcomes, only two of which are clear cut, being (7) encompasses (13) and vice versa.

In addition, to test whether bettors fully incorporate such a linear model of PP bias when making their betting decisions, a comparison is made using a LR test of the amount of information contained in two CL models. The first incorporates the log of the probabilities implied by final odds and a linear function of PP of the following form:

$$
p_{i j}=\frac{\exp \left(\delta m_{i j}+\lambda \ln \left(p_{i j}^{s}\right)\right)}{\sum_{i=1}^{n_{j}} \exp \left(\delta m_{i j}+\lambda \ln \left(p_{i j}^{s}\right)\right)}
$$

The second, represented by Equation 9, simply incorporates the log of the probabilities implied by odds. If there is a significant difference between the maximum likelihoods of these two models, then this will imply that linear PP bias effects are not fully incorporated into individuals' betting decisions.

\section{Results}

For all the models estimated across the whole period (1995-2000), it is found that $g\left(m_{i j}\right.$, $\left.D_{j}\right)$ and $h\left(m_{i j}, D_{j}\right)$ are reasonably well-approximated by allowing the mean index function of $m_{i j}$ to equal 0.5 . As races run at Wolverhampton are an average length of 1760 yards, this implies that $x$ and $y=3520$. Consequently, throughout the rest of this section it is only when examining changes in the PP bias from year to year that the more complex forms of $g\left(m_{i j}, D_{j}\right)$ and $h\left(m_{i j}, D_{j}\right)$ are invoked and parameters $x$ and $y$ are then estimated by maximizing the LL with respect to $\mathrm{x}$ and $\mathrm{y}$ using a grid search.

\section{Post-Position Bias Model}

The first set of results are obtained by estimating two CL models using data for the period 1995-2000; the first (9) simply incorporates odds probabilities, and the second (10) incorporates odds probabilities together with PP bias factors. The results are given in Table 1 and indicate that the LRs of both models are significant at the $1 \%$ level, suggesting that they both incorporate a 
Table 1. Comparison of Models Incorporating (a) Odds Probabilities, (b) Odds Probabilities and Post-Position Bias Factors, and (c) Post-Position Bias Factors for 1995-2000

\begin{tabular}{|c|c|c|c|c|c|c|}
\hline \multirow[b]{2}{*}{ Variable } & \multicolumn{2}{|c|}{$\begin{array}{l}\text { Odds Probabilities } \\
\text { Model (9) }\end{array}$} & \multicolumn{2}{|c|}{$\begin{array}{l}\text { Post-Position Bias Factors }+ \\
\text { Odds Probabilities Model (10) }\end{array}$} & \multicolumn{2}{|c|}{$\begin{array}{l}\text { Post-Position Bias } \\
\text { Factors Model (7) }\end{array}$} \\
\hline & $\begin{array}{l}\text { Parameter } \\
\text { Estimate }\end{array}$ & $t$-Value & $\begin{array}{l}\text { Parameter } \\
\text { Estimate }\end{array}$ & $t$-Value & $\begin{array}{l}\text { Parameter } \\
\text { Estimate }\end{array}$ & $t$-Value \\
\hline Distance factor ${ }^{\mathrm{a}}$ & - & & 1.0 (fixed) & - & 1.0 (fixed) & \\
\hline Straights factor ${ }^{\mathrm{a}}$ & - & & -1.2036 & -1.19 & -1.6864 & -1.76 \\
\hline Bends factor ${ }^{\mathrm{a}}$ & - & & 0.5237 & 0.56 & 0.9599 & 1.07 \\
\hline $\ln \left(p_{i j}^{s}\right)$ & 1.1843 & $31.40 * *$ & 1.1841 & $31.34 * *$ & & \\
\hline \multicolumn{7}{|l|}{ Model statistics } \\
\hline Restricted LL & -4286.03 & & -4286.03 & & -4286.03 & \\
\hline Unrestricted LL & -3147.91 & & -3138.33 & & -3736.90 & \\
\hline Model LR ${ }^{\mathrm{b}}$ & $2276.24^{* *}$ & & $5424.60 * *$ & & $1098.26^{* *}$ & \\
\hline $\begin{array}{l}\text { Critical value } \\
\quad\left(\chi_{n}^{2}[0.01]\right)\end{array}$ & $6.64(n=1)$ & & $11.35(n=3)$ & & $9.21(n=2)$ & \\
\hline Pseudo- $R^{2}$ & 0.2655 & & 0.2676 & & 0.1280 & \\
\hline$N$ & 1671 & & 1671 & & 1671 & \\
\hline
\end{tabular}

a These factors are divided by 10,000 to enable the model to converge.

${ }^{\mathrm{b}}$ The LR statistic $=-2($ LLo - LLm), where LLo and LLm are the maximums of the likelihood function where the parameters are constrained to equal zero (restricted LL) and where there are no restrictions on the parameters (unrestricted LL), respectively. This statistic is distributed $\chi_{n}^{2}$, where $n$ is the number of parameters estimated in the unrestricted model.

** $p<0.01$.

significant amount of information useful in predicting winning probabilities. The standard errors indicate that the PP bias factors in (10) are not significant at the 5\% level, but this may be because the factors are correlated and/or because the LL is not approximated by a quadratic function closely enough for asymptotic theory to be entirely reliable in this case. However, there is sufficient evidence from a LR test comparing models (9) and (10) to suggest that the model incorporating the three PP factors and the subjective probabilities of bettors (revealed as odds) contains significantly more valuable information for predicting winners than the model that simply incorporates the subjective probabilities of bettors $\left(\mathrm{LR}=19.16, \chi_{2}^{2}[0.01]=9.21\right)$. This suggests that bettors do not fully account for PP bias in their probability judgments.

The results of estimating the PP bias model (7) are also presented in Table 1. These indicate that the model's LR is highly significant $\left(\mathrm{LR}=1098.26, \chi_{2}^{2}[0.01]=9.21\right)$ and the pseudo- $R^{2}$ statistic suggests that the model accounts for an estimated 12.80 "empirical percent explained uncertainty" (Hauser 1978) of the variation in winning probabilities. This confirms that PP bias has an important influence on race outcome. In order to determine the degree to which PP bias is accounted for in bettors' decisions, the $R^{2}$ of model (9) is subtracted from the $R^{2}$ of model (10). The result, $0.21 \%$, represents the explanatory power of PP bias not accounted for in the bettors' decisions. It was indicated above that PP alone accounts for $12.80 \%$ of the variation in winning probabilities and, consequently $(12.80-0.21) / 12.80=98.36 \%$ of the explanatory power of PP is accounted for in bettors' subjective probability judgments.

\section{Changing Nature of Post-Position Bias through Time}

The results of estimating the PP bias model (7) for each of the years between 1995 and 2000 are presented in Table 2. The model LR statistics demonstrate that in each year PP bias 
Table 2. Estimated Parameter Values of Annual PP Bias Models (7) ${ }^{\mathrm{a}}$

\begin{tabular}{|c|c|c|c|c|c|c|c|}
\hline \multirow[b]{2}{*}{ Year } & \multirow[b]{2}{*}{$\operatorname{LR} \chi^{2}(4)^{\mathrm{b}}$} & \multirow[b]{2}{*}{$\begin{array}{l}\text { Pseudo } \\
R^{2}\end{array}$} & \multirow[b]{2}{*}{$\underset{\text { (races) }}{\mathrm{N}}$} & \multicolumn{4}{|c|}{ Parameter Estimates $^{\mathrm{c}}$} \\
\hline & & & & $\begin{array}{c}\text { Straights Factor } \\
(t-\text { Value })^{\mathrm{f}} \\
{[t-\text { Value }]^{\mathrm{f}}}\end{array}$ & $\begin{array}{c}\text { Bends Factor }^{\mathrm{d}} \\
(t \text {-Value })^{\mathrm{f}} \\
{[t \text {-Value }]^{\mathrm{f}}}\end{array}$ & $\begin{array}{c}\text { Index Value }^{\mathrm{e} x} \\
- \\
{\text { [t-Value }]^{\mathrm{g}}}^{\mathrm{s}}\end{array}$ & 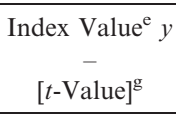 \\
\hline \multirow[t]{3}{*}{1995} & $225.34^{++}$ & 0.1471 & 299 & $-1.9916^{* *}$ & $0.26 \mathrm{D}-9$ & $3520 * *$ & $50 * *$ \\
\hline & & & & $(-4.72)$ & $(1.25)$ & - & - \\
\hline & & & & {$[-22.72]$} & {$[0.23]$} & {$[44.70]$} & {$[5.38]$} \\
\hline \multirow[t]{3}{*}{1996} & $152.04^{++}$ & 0.1082 & 272 & -0.7865 & $-0.14 \mathrm{D}-9$ & 16,520 & 320 \\
\hline & & & & $(-0.52)$ & $(-1.09)$ & - & - \\
\hline & & & & {$[-0.44]$} & {$[-0.04]$} & [0.23] & {$[0.02]$} \\
\hline \multirow[t]{3}{*}{1997} & $193.88^{++}$ & 0.1367 & 275 & -1.4186 & 0.2103 & 2520 & 1520 \\
\hline & & & & $(-2.69)$ & $(2.57)$ & - & - \\
\hline & & & & {$[-0.95]$} & {$[0.44]$} & [1.84] & [1.77] \\
\hline \multirow[t]{3}{*}{1998} & $214.10^{++}$ & 0.1428 & 290 & -2.2480 & 3.0110 & $2490 * *$ & 31,070 \\
\hline & & & & $(-2.03)$ & $(1.68)$ & - & - \\
\hline & & & & {$[-0.81]$} & {$[0.67]$} & {$[2.37]$} & [1.50] \\
\hline \multirow[t]{3}{*}{1999} & $192.58^{++}$ & 0.1248 & 298 & $-1.6314 * *$ & $-0.25 \mathrm{D}-10$ & $14,510 * *$ & $330 * *$ \\
\hline & & & & $(-1.16)$ & $(-3.03)$ & - & - \\
\hline & & & & {$[-13.33]$} & {$[-0.29]$} & [5.94] & [7.93] \\
\hline \multirow[t]{3}{*}{2000} & $158.08^{++}$ & 0.1290 & 237 & -0.0090 & 0.0009 & 3520 & $50 *$ \\
\hline & & & & $(-1.39)$ & $(1.34)$ & - & - \\
\hline & & & & {$[-0.21]$} & {$[0.17]$} & [1.45] & {$[1.90]$} \\
\hline \multicolumn{8}{|c|}{$\begin{array}{l}\text { a The standard errors of all the parameters are estimated using minus the Hessian matrix evaluated at the maximum of } \\
\text { the likelihood. }\end{array}$} \\
\hline \multirow{2}{*}{\multicolumn{8}{|c|}{ b The critical value of $\chi_{4}^{2}(0.01)=13.28$}} \\
\hline \multicolumn{2}{|c|}{ c The distance factor (D) remains fixed $(=1)$ in all annual models. } & & & & & & \\
\hline \multicolumn{8}{|c|}{ These factors are divided by 10,000 to enable the model to converge. } \\
\hline \multicolumn{8}{|c|}{$\begin{array}{l}\text { e To obtain these estimates, the LL was maximized with respect to } x \text { and } y \text { using a grid search. } \\
\text { f } t \text {-values (conditional) and [unconditional] on the estimated } x \text { and } y \text { values. }\end{array}$} \\
\hline \multicolumn{8}{|c|}{$\begin{array}{l}\text { Measures the number of standard errors } 1 / x \text { or } 1 / y \text { is from zero; this will not have (even asymptotically) a standard } t \\
\text { distribution as the model is not identified at zero. }\end{array}$} \\
\hline \multicolumn{8}{|c|}{$\begin{array}{l}{ }^{* *} \text { Unconditional } t \text {-values: } * * p<0.01, * p<0.05 \\
{ }^{+} p<0.01\end{array}$} \\
\hline
\end{tabular}

explains a significant amount of the variation in winning probabilities. However, the $R^{2}$ statistics show that the degree to which the model explains variation of winning probabilities changes substantially from year to year, even though the number of races remains fairly constant; the percentage changes in the fraction explained (i.e., $\left.R^{2}\right)$ being $-26.44 \%(1996 / 5),+$ $26.34 \%(1997 / 6),+4.46 \%(1998 / 7),-12.61 \%(1999 / 8),+3.37 \%(2000 / 1999)$. The parameter estimation procedure for model (7) is by grid search. Consequently, the standard errors and $t$ values are conditional on the grid values of the power to which $m$ is raised in the factors designed to capture information concerning the distance traveled on the straights ("straights factor") and the distance traveled on the bends ("bends factor"). In addition, unconditional standard errors for all parameters are determined by evaluating the analytic Hessian at the relevant points. It is found that the size and significance, using conditional and unconditional standard errors, of all the parameters vary substantially from year to year. In particular, the sign of the bends factor changed four times from 1995-2000. These differences in the size, significance, and sign of the parameters suggest that the influence of the different elements of PP bias captured by model (7) have a changing influence over time. This is confirmed by a LR test that demonstrates that the maximum LL obtained when estimating model (7) for all six 
years combined is less (i.e., more negative) than the sum of the maximum LLs obtained from estimating the model for each year separately $\left(\mathrm{LR}=36.62, \chi_{20}^{2}[0.05]=31.41\right)$. This result clearly demonstrates that if the coefficients of the parameters in the PP bias model are allowed to change from year to year, then the separate annual models better explain winning probabilities than a combined model for 1995-2000.

Taken together, these results confirm that PP bias changes substantially over the period 1995-2000 and that these changes are not uniform.

\section{Accounting for Changes in Post-Position Bias}

The extent to which the changes in PP bias are accounted for in individuals' probability judgments is explored by estimating models for each of the years 1995-2000, incorporating (i) odds and PP bias factors (10) and (ii) odds probabilities (9) and the results are displayed in Tables 3 and 4, respectively. LR tests that compare the maximum LL values of models (10) and (9) for each year from 1995-2000 yield the following values: 27.50, 2.72, 6.9, 11.72, 12.28, and 0.36 . These results indicate a significant difference in the amount of information concerning winning probabilities captured by models (10) and (9) at the $1 \%$ level in 1995 and, additionally, at the 5\% level $\left(\chi_{4}^{2}[0.05]=9.49\right)$ in 1998 and 1999. This suggests that bettors fully incorporated information concerning PP bias in their betting decisions in 1996, 1997, and 2000, and also, to a large extent, account for PP bias in 1998 and 1999. As was noted above, the parameter values in the comprehensive models incorporating PP bias (7) change from year to year. Consequently, it appears that bettors, in the majority of years, are able to adjust the model of PP bias that they employ to account for current circumstances.

The proportion of variation in winning probabilities explained by PP bias that is not captured in odds probabilities each year is determined by subtracting the $R^{2}$ of the odds-only model (9) from the $R^{2}$ of the odds and PP bias model (10) and dividing the result by the $R^{2}$ of the PP bias model (7). This procedure yields the following values for each year from 1995 2000, respectively: $0.1217,0.0120,0.0307,0.0357,0.0560$, and 0.0047 . These results indicate that other than in 1995 and 1999 (when $12.17 \%$ and $5.60 \%$ of variation in winning probabilities explained by PP bias were not accounted for in odds) more than $96 \%$ of the variation in winning probabilities explained by PP bias was accounted for in individuals' betting decisions.

In Table 4, features of the PP bias model (7), including whether the straights or bends factors are significant, the $R^{2}$ value of the model, and the annual change in the $R^{2}$ are compared with the degree to which PP bias is accounted for in bettors' decisions. These results indicate little obvious correlation between $R^{2}$ values associated with the PP bias model in year $t$ or $t-1$ and the degree to which bettors account for PP bias. For example, in 1995 (when odds do not fully account for PP bias), the $R^{2}$ value of the PP bias model is at its highest level; in 1999 (again, when odds do not fully account for PP bias), the PP bias model has the second-lowest $R^{2}$ value. Similarly, there appear to be no obvious associations between changes in the $R^{2}$ value of the PP bias model and the degree to which PP bias is accounted for in odds. However, in those years when neither the straights factor nor the bends factor is significant in the PP bias model, bettors largely account for PP bias in their decisions. Consequently, it is in the years when only one of these factors is significant that bettors do not fully account for PP bias in their decisions. 
Table 3. Estimated Parameter Values of Annual Models Incorporating PP Bias Factors and Odds Probabilities (10) ${ }^{\mathrm{a}}$

\begin{tabular}{|c|c|c|c|c|c|c|c|}
\hline \multirow[b]{2}{*}{ Year } & \multirow[b]{2}{*}{$\begin{array}{c}\text { Model LR } \\
\chi^{2}(5)^{\mathrm{b}}\end{array}$} & \multirow[b]{2}{*}{ Pseudo- $R^{2}$} & \multicolumn{4}{|c|}{ Parameter Estimates $^{\mathrm{c}}$} & \multirow[b]{2}{*}{$\begin{array}{c}\text { Index } \\
\text { Value }^{\mathrm{e}} y \\
- \\
{[t \text {-Value }]^{\mathrm{g}}}\end{array}$} \\
\hline & & & $\begin{array}{c}\ln (\text { Odds Probs) } \\
(t-\text {-Value })^{\mathrm{f}} \\
{[t-\text {-Value }]^{\mathrm{f}}}\end{array}$ & $\begin{array}{l}\text { Straights } \\
\text { Factor }^{\mathrm{d}} \\
(t \text {-Value })^{\mathrm{f}} \\
{[t \text {-Value }]^{\mathrm{f}}}\end{array}$ & $\begin{array}{l}\text { Bends Factor }{ }^{\mathrm{d}} \\
(t-\text {-Value })^{\mathrm{f}} \\
{[t-\text { Value }]^{\mathrm{f}}}\end{array}$ & $\begin{array}{c}\text { Index } \\
\text { Value }^{\mathrm{e}} x \\
- \\
{[t \text {-Value }]^{\mathrm{g}}}\end{array}$ & \\
\hline \multirow[t]{3}{*}{1995} & $447.82^{++}$ & 0.2917 & $1.2477 * *$ & $-1.9044^{* *}$ & $0.15 \mathrm{D}-8$ & $3320 * *$ & 50 \\
\hline & & & $(13.47)$ & $(-4.81)$ & $(1.35)$ & - & - \\
\hline & & & {$[12.13]^{\mathrm{h}}$} & {$[-1.25]^{\mathrm{h}}$} & {$[0.02]^{\mathrm{h}}$} & {$[2.55]^{\mathrm{h}}$} & {$[0.48]^{\mathrm{h}}$} \\
\hline \multirow[t]{3}{*}{1996} & $337.72^{++}$ & 0.2411 & $1.1611^{* *}$ & -1.2508 & $-0.22 \mathrm{D}-9$ & 19,520 & 320 \\
\hline & & & (12.49) & $(-0.52)$ & $(-0.45)$ & - & - \\
\hline & & & [12.49] & {$[-0.64]$} & {$[-0.58]$} & [0.27] & [0.02] \\
\hline \multirow[t]{3}{*}{1997} & $330.80^{++}$ & 0.2335 & $1.0148 * *$ & -1.7943 & 0.1255 & 3520 & 1520 \\
\hline & & & $(11.01)$ & $(-2.26)$ & $(2.18)$ & - & - \\
\hline & & & [11.01] & {$[-1.18]$} & {$[0.35]$} & {$[1.53]$} & {$[0.94]$} \\
\hline \multirow[t]{3}{*}{1998} & $418.36^{++}$ & 0.2810 & $1.1791^{* *}$ & -3.0449 & 5.3475 & $2760 * *$ & 4040 \\
\hline & & & (12.88) & $(-2.62)$ & $(2.23)$ & - & - \\
\hline & & & [12.88] & {$[-1.01]$} & {$[1.06]$} & [2.93] & {$[1.74]$} \\
\hline \multirow[t]{3}{*}{1999} & $453.22^{++}$ & 0.2957 & $1.2632 * *$ & -1.0777 & $-0.14 \mathrm{D}-10$ & 10,520 & 320 \\
\hline & & & $(14.20)$ & $(-0.84)$ & $(-3.21)$ & - & - \\
\hline & & & {$[14.20]$} & {$[-0.43]$} & {$[-0.06]$} & {$[0.38]$} & {$[0.05]$} \\
\hline \multirow[t]{3}{*}{2000} & $354.80^{++}$ & 0.2915 & $1.2671 * *$ & -0.3381 & $0.16 \mathrm{D}-9$ & 10,420 & 340 \\
\hline & & & $(12.48)$ & $(-0.25)$ & $(0.54)$ & - & - \\
\hline & & & {$[12.42]^{\mathrm{h}}$} & {$[-0.15]^{\mathrm{h}}$} & {$[0.01]^{\mathrm{h}}$} & {$[0.09]^{\mathrm{h}}$} & {$[0.18]^{\mathrm{h}}$} \\
\hline
\end{tabular}

${ }^{\text {a }}$ The standard errors of all the parameters are estimated using minus the Hessian matrix evaluated at the maximum of the likelihood.

${ }^{\mathrm{b}}$ The critical value of $\chi_{5}^{2}(0.01)=15.09$.

${ }^{c}$ The distance factor (D) remains fixed $(=1)$ in all annual models.

$\mathrm{d}$ These factors are divided by 10,000 to enable the model to converge.

e To obtain these estimates, the LL was maximized with respect to $x$ and $y$ using a grid search.

${ }^{\mathrm{f}} t$-values (conditional) and [unconditional] on the estimated $x$ and $y$ values.

${ }^{\mathrm{g}}$ Measures the number of standard errors $1 / x$ or $1 / y$ is from zero; this will not have (even asymptotically) a standard $t$ distribution as the model is not identified at zero.

${ }^{\mathrm{h}}$ Standard errors estimated using OPG (outer product of gradient) method, where the analytic Hessian was not positive definite.

* Unconditional $t$-values: $p<0.05$.

** Unconditional $t$-values: $p<0.01$.

${ }^{++} p<0.01$.

\section{Historical Model of Post-Position Bias}

The results of estimating CL models based on an historical model of PP bias (12) for each year 1996-2000 are given in Table 5. The standard errors imply the historical bias factors in each of the annual models are not significant at 5\% using a Wald test, but this may be because, once again, the LL is not approximated by a quadratic function closely enough for asymptotic theory to be entirely reliable in this case. However, there is sufficient evidence from the model LR tests to conclude that these historical PP bias models account for a significant amount of variation in winning probability and the $R^{2}$ values range between 0.1078 and 0.1372 .

Models for each year incorporating (i) historical model probabilities and odds probabilities (11) and (ii) odds probabilities (9) are estimated and the results are also displayed in Table 5. LR tests comparing these models (i.e., Eqns. 9 and 11) suggest that information 
Table 4. Estimated Parameter Values and Goodness of Fit Statistics of Annual Models Incorporating Odds Probabilities (9)

\begin{tabular}{lcccccccc}
\hline & $\begin{array}{c}\text { Parameter Estimate: } \\
\text { Ln(Odds Probs) } \\
(t \text {-Value })\end{array}$ & $\begin{array}{c}\text { Model LR } \\
\chi^{2}(1)^{\mathrm{a}}\end{array}$ & $\begin{array}{c}\text { Statistics: } \\
\text { Pseudo- } R^{2}\end{array}$ & $\begin{array}{c}\text { Proportion of } \\
\text { PP Bias Not } \\
\text { Accounted for } \\
\text { in Odds }\end{array}$ & $\begin{array}{c}\text { Pseudo- } R^{2} \\
\text { of PP } \\
\text { Model }(7)\end{array}$ & $\begin{array}{c}\text { Change in } \\
R^{2} \text { from } \\
\text { Previous Year }\end{array}$ & $S$ & $B$ \\
\hline 1995 & $1.2335^{* *}(13.46)$ & $420.32^{* *}$ & 0.2738 & $0.1217^{+}$ & 0.1471 & & $\mathrm{Y}$ & $\mathrm{N}$ \\
1996 & $1.1556^{* *}(12.45)$ & $335.00^{* *}$ & 0.2398 & 0.0120 & 0.1082 & -26.44 & $\mathrm{~N}$ & $\mathrm{~N}$ \\
1997 & $1.0233^{* *}(11.11)$ & $323.90^{* *}$ & 0.2293 & 0.0307 & 0.1367 & +26.34 & $\mathrm{~N}$ & $\mathrm{~N}$ \\
1998 & $1.1707^{* *}(12.88)$ & $406.64^{* *}$ & 0.2730 & $0.0357^{++}$ & 0.1428 & +4.46 & $\mathrm{~N}$ & $\mathrm{~N}$ \\
1999 & $1.2518^{* *}(14.19)$ & $440.96^{* *}$ & 0.2882 & $0.0560^{+}$ & 0.1248 & -12.61 & $\mathrm{Y}$ & $\mathrm{N}$ \\
2000 & $1.2668^{* *}(12.49)$ & $354.08^{* *}$ & 0.2909 & 0.0047 & 0.1290 & +3.37 & $\mathrm{~N}$ & $\mathrm{~N}$ \\
\hline
\end{tabular}

$S$ : Straights factor significant at $5 \% ; B$ : Bends factor significant at $5 \%$.

a The critical value of $\chi_{1}^{2}(0.01)=6.64$.

${ }^{++,+}$Indicate for LR test results comparing the maximum LL values of models incorporating (a) odds and PP bias factors (10) with (b) odds probabilities (9): $p<0.05\left(^{+}\right)$, and $p<0.01\left({ }^{++}\right)$. $* * p<0.01$.

from the historical models is fully accounted for in bettors' probability judgments in each of the five years $\left(\mathrm{LR}=0.5,0.72,2.90,3.38\right.$, and 0.12 for $1996-2000$, respectively; $\chi_{4}^{2}[0.05]=9.49$ ). This result is confirmed by comparing the $R^{2}$ values of the two models in each year. The percentage of variation in winning probabilities explained by the historical model that is accounted for in odds varies between $98.39 \%$ and $100 \%$.

A comparison of the results of estimating models incorporating (i) current-year PP bias factors (7), given in Table 2, and (ii) historical PP bias factors (12), displayed in Table 5, suggests that model (7) contains more information than model (12) ( $\mathrm{LR}=1.08,8.70,8.72,7.1$, and 2.32 for 1996-2000, respectively) in most years, even though a formal LR test cannot be performed as the models are not nested. The $R^{2}$ value for model (7) is greater than the $R^{2}$ value for the corresponding year of the historical model (12) for each of the years 1995-2000. Consequently, a sign test suggests that a model incorporating current PP bias factors (7) explains a significantly (at the $5 \%$ level) greater proportion of winning probability than a model based on historical PP bias factors (12).

\section{Linear Model of Post-Position Bias}

The results of estimating a linear model of PP bias (13) for the whole period 1995-2000 and for each of the individual years are given in Table 6. The LR statistics of these models suggest that the simplified model of PP bias accounts for a significant proportion of the variation in winning probabilities of horses throughout the period; the $R^{2}$ values of these models ranging from 0.1086 to 0.1438 . However, an encompassing test confirms that the more comprehensive model of PP bias (7) for the whole period accounts for a significantly greater proportion of variation in winning probabilities of horses than the linear model (13) LR of nested model (involving parameters in the comprehensive and linear models) versus comprehensive model $=3.42\left(\chi_{1}^{2}[0.05]=3.84\right)$, implying that the comprehensive model encompasses the linear model; LR of nested model (involving parameters in the comprehensive and linear models) versus linear model $=6.65\left(\chi_{1}^{2}[0.05]=3.84\right)$, implying that the linear model does not encompass the comprehensive model. 

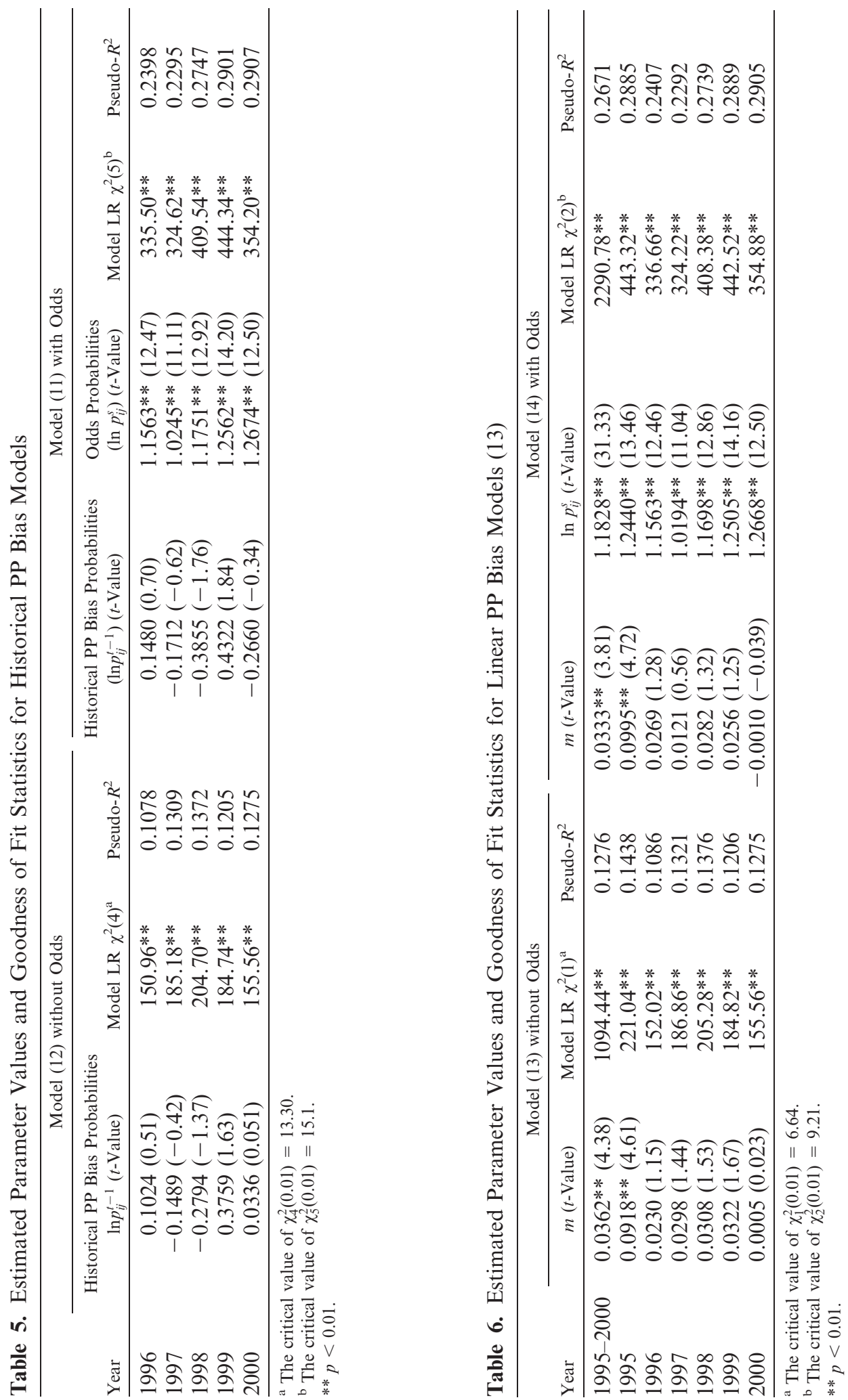
An assessment of the degree to which individuals account for this linear model of PP is obtained by comparing the results of estimating CL models incorporating (i) probabilities implied by final odds and a linear function of PP (14), the results of which are also given in Table 6, and (ii) probabilities implied by odds alone (9), the results of which are given in Table 1 for 1995-2000 combined and in Table 4 for each of the individual years. Comparing the maximum LLs of models (14) and (9) yields the following results for the whole period and for each year from 1995-2000, respectively: $L R=14.54,23.00,1.66,0.32,1.74,1.56$, and $0.80 ; \chi_{1}^{2}(0.05)=3.84$. It appears that while for all six years combined the simple linear effect of PP bias is not fully accounted for in bettors' decisions, this largely arises because the linear effect is not accounted for in 1995. From 1996 onwards the linear PP effect is fully discounted in odds.

In a similar manner to that discussed above, the proportion of variation in winning probabilities explained by the linear PP bias effect not captured in odds probabilities each year is determined by subtracting the $R^{2}$ of the odds only model (9) from the $R^{2}$ of the odds and linear PP bias model (14) and dividing the result by the $R^{2}$ of the linear PP bias model (13). This procedure yields the following values for each year from 1995-2000, respectively: 0.1024, $0.0081,0.0008,0.0065,0.0058$, and 0.0030 . In 1995, over $10 \%$ of the variation in winning probabilities explained by a linear PP bias model was not captured within odds, but in subsequent years, bettors' decisions account for over $99 \%$ of this variation, with a trend to capture more of the information in later years.

\section{Discussion}

Three key findings emerge from the results: First, bettors are skilled in effectively accounting for changing PP bias information in their betting decisions, even though the changes in track management practices that influence the bias are not announced. Second, bettors appear to learn through experience to account for this dynamic information. Third, bettors adopt effective simplification strategies to cope with the complexity of dynamic information. Each of these findings is now explored in turn.

\section{Effective Use of Sporadically Changing Information}

Throughout the period 1995-2000, PP bias accounted for an average of $12.80 \%$ of the variation in winning probabilities and $98.36 \%$ of this variation was accounted for in bettors' decisions. In three out of the six years examined, bettors' probability judgments fully accounted for a comprehensive model of PP bias using current year's data, and they largely accounted for it in two further years. They achieved this despite substantial changes from year to year in the degree to which the comprehensive model of PP bias explained winning probabilities, and the sign, size, and significance of factors designed to capture information concerning differential PP advantages attributable to the distance traveled on straights and bends, respectively. In addition, bettors were able to adjust their own PP bias models despite the fact that many of the racetrack management procedures responsible for the changing PP bias were not announced to the public. These results are in line with studies conducted by Canfield, Fauman, and Ziemba (1987) and Betton (1994). 
Bettors' ability to utilize the changing information set in their probability judgments may result from a number of factors shown to be associated with good calibration. First, bettors have a strong motivation to make accurate probability judgments as their own financial resources and often their peer group esteem depend on the outcome of their decisions (Saunders and Turner 1987). Previous research confirms the premise that judgments improve when incentives are provided (Beach et al. 1987; Ashton 1992; Waller et al. 1999).

Second, experience and domain-specific knowledge have been shown to be associated with accurate probability judgments (e.g., Joyce and Biddle 1981; Smith and Kida 1991). Most individuals who bet with bookmakers are familiar with the betting task (Johnson and Bruce 2001) and undertake considerable research to assess the factors that may influence race outcome (Neal 1998). In addition, experienced horserace bettors often act in a cognitively sophisticated manner, incorporating data in a complex cognitive model (Ceci and Liker 1986). They also have the advantage that those who frequently make probability judgments are often better calibrated (Ferrell 1994).

Third, it has been suggested that the accuracy of probability judgments is often better in natural rather than laboratory settings (Beach et al. 1987; Bazerman 1994; Ferrell 1994), and earlier research has demonstrated that betting behavior differs significantly between laboratory and real world environments (Anderson and Brown 1984).

Two further factors may help to explain bettors' apparent ability to account for the dynamic and often implicit PP information: "recency" and the predictive nature of the task. Recency can cause biases in some contexts, but it may help individuals to adjust more rapidly to structural shifts which can occur in dynamic information sets (e.g., Ashton and Kennedy 2002). In addition, bettors' probability judgments are predictions, and calibration associated with prediction has been shown to be more accurate than that related to an individual's perception of their memory accuracy (Wright and Ayton 1988).

In summary, there are a number of factors associated with the judgment task, the task environment, and the nature of experienced bettors that are favorable to accurate probability judgments. The results reported here suggest that under these favorable conditions bettors are skilled in accounting for a dynamic information set even when alterations in the underlying mechanisms that cause these changes are not made public.

\section{Learning to Cope with Sporadically Changing Information}

The results of the current study may provide evidence that bettors learn, through outcome feedback, to cope with changing information. Outcome feedback often has a positive effect on the accuracy of probability judgments because it allows decision makers to learn which cues are important (McClelland and Bolger 1994; Koehler 1996). This particularly occurs in real world environments where individuals learn through observation to identify what data is redundant and unreliable and what cognitive models are most applicable (McClelland and Bolger 1994). Practice with homogeneous tasks also improves probability judgments, particularly where forecasting is performed on a repetitive and sequential basis (Lock 1987) because this allows individuals to learn judgment relevant cues (McClelland and Bolger 1994). Similarly, violations of rational choice are often reduced where judgments and feedback occur regularly (Keren 1991). There is a high degree of uniformity between betting markets and bettors can engage repeatedly in a similar task, allowing them to become familiar with the processes and outcomes 
of the market. This enables them to develop an effective basis for interpreting dynamic market information. Goodwin and Wright (1992, p. 215) observe that "performance-demonstrated expertise in probability judgments is underpinned by practice and regular performance feedback" and horserace betting markets provide bettors with just these conditions. Outcome feedback per se is not sufficient for good probability judgments, as is evidenced by poor calibration observed amongst physicians who receive delayed and non-uniform feedback (Bennett 1980). However, bettors receive uniform and immediate outcome feedback that is unambiguous.

We find that bettors' judgments fully account for a comprehensive model of PP bias based on the previous year's results and that bettors account for a large proportion of the current year PP bias in their probability judgments. However, there are three years - 1995, 1998, and 1999when a significant amount of current-year PP bias is not accounted for in their judgments. Bettors' inability to fully account for the bias in 1995 may have resulted from a lack of outcome feedback, as the racetrack had only been operating for one year. In addition, research suggests that individuals tend to discount evidence that runs counter to existing perceptions (Harries et al. 2004). Consequently, it is likely that in the first year of racetrack operation (1994) bettors, based on the configuration of the track, would have expected horses with PP close to the inside to have a natural advantage. This expectation may have been reinforced by horseracing publications, as a common view of racing journalists is that small tracks with tight bends, like Wolverhampton, will exhibit such a bias. Beyer (1983), for example, observes that horses with an inside PP on such tracks invariably have an advantage. However, one leading racing publication, Raceform (1995, p. xxxiii), reporting on the Wolverhampton results in 1994 states: "high numbers have a marked advantage on the new fiber-sand course." Consequently, the first year's results did not conform to the cognitive model derived from horserace publications and their own observation of the track configuration. Under these circumstances, it is likely that some of the outcome feedback would have been ignored when forming judgments in the following year (1995). Further outcome feedback in 1995 may have helped to develop a new cognitive model that accounted for the outside PP having an advantage. A comprehensive model of PP bias was then fully accounted for in bettors' probability judgments in 1996 and 1997. Despite this, bettors did not fully account for current year's PP bias in 1998 and 1999 when they already had four years of outcome feedback. However, in 1998 and 1999 they did fully account for the PP bias observed from the previous year (see section 4.4). In addition, the degree to which they accounted for variation in winning probabilities explained by current year PP bias in 1999 was significantly greater than in 1995 (93.99\% cf. 87.83\%). These results suggest that outcome feedback may have been employed to improve performance in these later years. In fact, in 2000, bettors' probability judgments again fully accounted for information regarding current year PP bias derived from a comprehensive current-year model of the phenomenon.

\section{Simplification Strategies to Handle Sporadically Changing Information}

The results suggest that the simplified linear model of PP bias does not capture all the information contained in a comprehensive model of PP over the whole period 1995-2000. However, the linear approximation of the PP bias appears to be a reasonable model for bettors to employ because it captures $12.76 \%$ of the variation in winning probabilities over the period 1995-2000 compared with $12.80 \%$ for the comprehensive model. In addition, we find that 
bettors account for $90 \%$ of the variation in winning probabilities explained by a linear PP bias model in their probability judgments in 1995 , then $99.2 \%, 99.9 \%, 99.35 \%, 99.4 \%$, and $99.7 \%$, respectively, in subsequent years. The general trend to incorporate more of the changing information captured by this linear model over time suggests that bettors may employ a linear model of PP as an input to their cognitive model of this phenomenon. It should also be noted that the values of the model parameters change each year. Consequently, it appears that bettors are able to adapt the linear model they employ to meet current circumstances. This also lends some support to the notion that bettors learn to improve the model they employ through outcome feedback.

Subsequent to 1995, bettors' probability judgments fully incorporate (at a 1\% level of significance) a comprehensive model of current year's PP bias. In addition, a model incorporating current year's PP bias ([7], see Table 2) explains more of the variation in winning probabilities in each of the years 1996-2000 than an historical model of PP ([12], see Table 5). These results suggest that bettors do not simply mimic the previous year's PP bias in their betting decisions; rather, they appear to learn to adapt the model to the bias experienced in the current year.

It has been observed that individuals operating in familiar task domains can become attuned to these environments. Under these circumstances individuals are capable of adopting simple, efficient heuristics that capture the features that are essential to good decision making (Gigerenzer 2004). In particular, it is argued that evolution equips individuals to handle information in the form of frequencies in the natural environments in which they make decisions (Gigerenzer 1996, 2000). This research evidence is largely based on supplied frequencies rather than those acquired through outcome feedback. Edgell et al. (2004, p. 213) found that "experience with the environment is not always sufficient for good performance." Consequently, it may well be that bettors acquire their understanding of PP bias from "natural sampling": observation of the winning frequencies of certain PP, together with more codified win frequency information and narrative accounts of the bias from racing publications. In fact, because several racing publications provide a similar account of the PP bias at Wolverhampton, it is likely that this information is afforded greater scrutiny than if it came from a single source (Harkins and Petty 1987). Finally, it is possible that explanations for PP bias given in racing publications provide more understanding of the reasons for the bias, and it has been shown that cognitive information feedback of this sort can assist learning more than simple outcome feedback (Remus et al. 1996).

\section{Conclusion}

The principal aims of this article were to identify to what extent and in what manner bettors' probability judgments account for dynamic, implicit information. The results offer an interesting insight into individuals' information-processing abilities. They suggest that at least some groups of decision makers, operating in certain domains, are skilled in accounting for dynamic information in their probability judgments. In particular, the results indicate that U.K. horserace bettors are able to adopt efficient heuristics to cope with dynamic information, which is subject to structural shifts and where the underlying causal mechanisms (e.g., changing racetrack management practices) are not formally made known to them. Under these 
conditions bettors appear to learn to adapt the models they employ to capture the evolving information. It is suggested that a number of factors contributed towards creating a favorable setting for the effective utilization of a dynamic information set. These include: strong incentives, the decision makers' experience in the task domain, the nature of the task (e.g., prediction), and the nature of the task environment (i.e., a naturalistic setting). In addition, it is argued that the unequivocal and uniform nature of outcome feedback together with cognitive information feedback may have assisted the bettors in learning to adapt their cognitive models as the information set evolved. This research examined bettors' skill in adapting to dynamic PP information over a five-year period. It is possible that outcome feedback over a longer period may enable bettors to develop even more sophisticated coping mechanisms. The continuing dynamic nature of PP bias at Wolverhampton since 2000 will provide an ideal setting for such research.

The results reported here should provide some comfort for regulators that bettors are able to adapt their decision-making behavior to cope with even hostile information environments. Specifically, in relation to bettors' ability to detect and react to PP biases, there appears no immediate need for additional regulation to force racetrack operators to disclose more information concerning their track management practices. More generally, the results may question the need for further restrictive regulation in horseracing concerning information disclosure, which various commentators have called for, relating to such factors as the body weight of horses, sectional timing in races, and scientific measurement of the "going."

The ability to make appropriate probability judgments in the face of dynamic information is vital in many areas of human activity. The results reported here suggest that individuals under certain conditions may have this ability, but it is not clear whether these results are transferable to other decision domains or to other groups of decision makers. Further research in other domains is clearly needed. However, the quest to isolate those factors that can improve probability judgments in dynamic environments is clearly an important one. While the current study does not permit the isolation and manipulation of the factors that it is suggested may have enhanced performance in this study, there is scope for subsequent laboratory studies to shed further light on their respective influences. Such work could have important implications for regulators who are seeking to develop a careful balance between restrictive regulation that forces the disclosure of detailed information and a light touch that allows free markets to flourish.

\section{References}

Anderson, G., and R. I. F. Brown. 1984. Real and laboratory gambling, sensation-seeking, and arousal. British Journal of Psychology 75:401-10.

Ashton, R. H., and J. Kennedy. 2002. Eliminating recency with self review: The case of auditors' 'going concern' judgments. Journal of Behavioral Decision Making 15:221-31.

Ashton, R. H. 1992. Effects of justification and a mechanical aid on judgment performance. Organizational Behavior and Human Decision Processes 52:292-306.

Ayton, P., and G. Wright. 1994. Subjective probability: What should we believe? In Subjective probability, edited by G. Wright and P. Ayton. Chichester, UK: Wiley, pp. 163-83.

Balzer, W. K., L. B. Hammer, K. E. Sumner, T. R. Birchenough, S. P. Martens, and P. H. Raymark. 1994. Effects of cognitive feedback components, display format, and elaboration on performance. Organization Behavior and Human Decision Processes 58:369-85. 
Baranski, J. V., and W. M. Petrusic. 1994. The calibration and resolution of confidence in perceptual judgments. Perception and Psychophysics 55:412-28.

Baranski, J. V., and W. M. Petrusic. 1995. On the calibration of knowledge and perception. Canadian Journal of Experimental Psychology 49:397-407.

Bazerman, M. H. 1994. Judgment in managerial decision-making. Chichester, UK: Wiley.

Beach, L. R., J. Christensen-Szalanski, and V. Barnes. 1987. Assessing human judgment: Has it been done, can it be done, should it be done? In Judgmental forecasting, edited by G. Wright and P. Ayton. Chichester, UK: Wiley, pp. 49-62.

Bennett, M. J. 1980. Heuristics and the weighting of base rate information in diagnostic tasks by nurses. Unpublished doctoral dissertation. Monash University, Australia.

Betton, S. 1994. Post-position bias: An econometric analysis of the 1987 season at Exhibition Park. In Efficiency of Racetrack Betting Markets, edited by D. B. Hausch, V. S. Y. Lo, and W. T. Ziemba. London: Academic Press, pp. 511-26.

Beyer, A. 1983. The winning horseplayer. Boston, MA: Houghton-Mifflin Co.

Bolger, F., and N. Harvey. 1993. Context-sensitive heuristics in statistical reasoning. Quarterly Journal of Experimental Psychology 46:779-811.

Canfield, B. R., B. C. Fauman, and W. T. Ziemba. 1987. Efficient market adjustment of odds prices to reflect track biases. Management Science 33:1428-39.

Ceci, S. J., and J. K. Liker. 1986. A day at the races: A study of IQ, expertise and cognitive complexity. Journal of Experimental Psychology: General 115:255-66.

Chinander, K. R., and M. E. Schweitzer. 2003. The input bias: The misuse of input information in judgments of outcomes. Organizational Behavior and Human Decision Processes 91:243-53.

Cohen, M. S. 1993. The naturalistic bases of decision biases. In Decision making in action: Models and methods, edited by G. A. Klein, J. Orasanu, R. Calderwood, and C. E. Zsambok. Norwood, NJ: Ablex, pp. 51-99.

Cotton, M. 1990. Value betting. Oswestry: Ausculus Press.

Dalrymple, D. J. 1987. Sales forecasting practices, results from a United States survey. International Journal of Forecasting 3:379-91.

Edgell, S. E., J. I. Harbison, W. P. Neace, I. D. Nahinsky, and A. S. LaJoie. 2004. What is learned from experience in a probabilistic environment? Journal of Behavioral Decision Making 17:213-29.

Ferrell, W. R. 1994. Discrete subjective probabilities and decision analysis: Elicitation, calibration and combination. In Subjective probability, edited by G. Wright and P. Ayton. Chichester, UK: Wiley, pp. 410-51.

Figlewski, S. 1979. Subjective information and market efficiency in a betting market. Journal of Political Economy $87: 75-88$.

Fildes, R. 1991. Efficient use of information in the formation of subjective industry forecasts. Journal of Forecasting 10:597-617.

Ford, J. K., N. Schmitt, S. L. Schectman, B. M. Hills, and M. L. Doherty. 1989. Process tracing methods: Contributions, problems and neglected research questions. Organizational Behavior and Human Decision Processes 43:75-117.

Gigerenzer, G. 2004. Fast and frugal heuristics: The tools of bounded rationality. In Judgment \& Decision making, edited by D. J. Koehler and N. Harvey. Malden, MA: Blackwell Publishing.

Gigerenzer, G. 2000. Adaptive thinking: Rationality in the real world. New York: Oxford University Press.

Gigerenzer, G. 1996. On narrow norms and vague heuristics: A reply to Kahneman and Tversky. Psychological Review 103:592-6.

Gigerenzer, G., U. Hoffrage, and H. Kleinbolting. 1991. Probabilistic mental models: A Brunswikian theory of confidence. Psychological Review 98:506-28.

Goodwin, P., and G. Wright. 1992. Decision analysis for management judgment. Chichester, Sussex: W. Hey.

Griffin, D., and A. Tversky. 1992. The weighting of evidence and the determinants of confidence. Cognitive Psychology 24:411-35

Harkins, S., and R. Petty. 1987. Information utility and the multiple source effect. Journal of Personality and Social Psychology 52:260-68.

Harries, C., I. Yaniv, and N. Harvey. 2004. Combining advice: The weight of dissenting opinion in the consensus. Journal of Behavioral Decision Making 17:333-48.

Harvey, N., F. Bolger, and A. McClelland. 1994. On the nature of expectations. British Journal of Psychology 85:203-29.

Hauser, J. R. 1978. Testing the accuracy, usefulness and significance of probabilistic choice models: An informationtheoretic approach. Operations Research 26:406-21.

Hoffrage, U., G. Gigerenzer, S. Kraus, and L. Martignon. 2002. Representation, facilities reasoning: What natural frequencies are and what they are not. Cognition 84:343-52.

Hogarth, R. M. 1987. Judgment and choice. 2nd edition. New York: Wiley.

Hong, Y., and C. Chiu. 1988. Sex, locus of control and illusion of control in Hong Kong as correlates of gambling involvement. The Journal of Social Psychology 128:667-73. 
Johnson, J. E. V., and A. C. Bruce. 2001. Calibration of subjective probability judgments in a naturalistic setting. Organizational Behavior and Human Decision Processes 85:265-90.

Jones, S. K., T. J. Yurak, and D. Frisch. 1997. The effect of outcome information on the evaluation and recall of individuals' own decisions. Organizational Behavior and Human Decision Processes 71:95-120.

Joyce, E. J., and G. C. Biddle. 1981. Anchoring and adjustment in probabilistic inference in auditing. Journal of Accounting Research 19:120-45.

Kahneman, D., P. Solvic, and A. Tversky. 1982. Judgment under uncertainty: Heuristics and biases. Cambridge, UK: Cambridge University Press.

Keren, G. 1991. Calibration and probability judgments: Conceptual and methodological issues. Acta Psychologica 77:217-73.

Kleinmutz, B. 1990. Why we will use our heads instead of formulas: Towards an integrative approach. Psychological Bulletin 107:296-310.

Koehler, J. J. 1996. The base rate fallacy reconsidered: Descriptive, normative, and methodological challenges. Behavioral and Brain Sciences 19:1-15.

Kopelman, R. E. 1986. Objective feedback. In Generalizing from laboratory to field settings, edited by E. A. Locke. Lexington, MA: Lexington Books.

Law, D., and D. A. Peel. 2002. Insider trading, herding behavior and market plungers in the British horse-race betting market. Economica 69:327-38.

Lock, A. 1987. Integrating group judgments in subjective forecasts. In Judgmental forecasting, edited by G. Wright and P. Ayton. Chichester, UK: Wiley, pp. 109-27.

Maddala, G. S. 1993. Limited dependent and qualitative variables in econometrics. Cambridge, UK: Cambridge University Press.

Malhotra, N. K. 1982. Information load and consumer decision making. Journal of Consumer Research 8:419-30.

McClelland, A. G. R., and F. Bolger. 1994. The calibration of subjective probabilities: Theories and models 1980-94. In Subjective probability, edited by G. Wright and P. Ayton. Chichester, UK: Wiley, pp. 453-82.

McFadden, D. 1974. Conditional logit analysis of qualitative choice behaviour. In Frontiers in econometrics, economic theory and mathematical economics, edited by P. Zarembka. New York: Academic Press.

Mizon, G. E., and J-F. Richard. 1986. The encompassing principle and its application in econometrics. Econometrica 54:657-78.

Mocan, H. N., and S. Azad. 1995. Accuracy and rationality of state general fund revenue forecasts: Evidence from panel data. International Journal of Forecasting 11:417-28.

Murphy, A. H., and B. G. Brown. 1985. A comparative evaluation of objective and subjective weather forecasts in the United States. In Behavioral decision making, edited by G. Wright. New York: Plenum, pp. 178-93.

Neal, M. 1998. You lucky punters! A study of gambling in betting shops. Sociology 32:581-600.

Orasanu, J., and T. Connolly. 1993. The reinvention of decision making. In Decision making in action: Models and methods, edited by G. A. Klein, J. Orasanu, R. Calderwood, and C. E. Zsambok. Norwood, NJ: Ablex.

Paton, D., D. S. Siegel, and L. Vaughan Williams. 2009. The growth of gambling and prediction markets: Economic and financial implications. Economica 76:219-24.

Raceform. 1995. Flat annual for 1996. Newbury, UK: Raceform Ltd.

Remus, W. E., M. J. O'Conner, and K. Griggs. 1995. Will reliable information improve the accuracy of judgmental forecasts? International Journal of Forecasting 11:185-293.

Remus, W. E., M. J. O'Conner, and K. Griggs. 1996. Does feedback improve the accuracy of recurrent judgmental forecasts? Organizational Behavior and Human Decision Processes 66:22-30.

Sanders, N. R., and K. B. Manrodt. 1994. Forecasting practices in U.S. corporations: Survey results. Interfaces 24:29-100.

Sanders, N. R. 1997. The impact of task properties feedback on time series judgmental forecasting tasks. Omega: International Journal of Management Science 25:135-44.

Sauer, R. D. 1998. The economics of wagering markets. Journal of Economic Literature XXXVI:2021-64.

Saunders, D. M., and D. E. Turner. 1987. Gambling and leisure: The case of racing. Leisure Studies 6:281-9.

Shin, H. S. 1993. Measuring the incidence of insider trading in a market for state-contingent claims. Economic Journal 103:1141-53.

Smith, J. F., and T. Kida. 1991. Heuristics and biases: Expertise and task realism in auditing. Psychological Bulletin 109:472-85.

Snyder, W. 1978. Horse-racing: The efficient markets model. Journal of Finance 78:1109-18.

Soll, J. B. 1999. Intuitive theories of information: Beliefs about the value of redundancy. Cognitive Psychology 38:317-46.

Suantek, L., F. Bolger, and W. R. Ferrell. 1996. The hard-easy effect in subjective probability calibration. Organizational Behavior and Human Decision Processes 67:201-21.

Superform. 1996. Races and racehorses. Shoreham, UK: Furlong Press. 
Superform. 2000. Races and racehorses. Shoreham, UK: Furlong Press.

Taranto, G. M. 1989. Sales forecasting practices: Results from an Australian survey. Unpublished thesis, University of New South Wales.

Timmermans, D. 1993. The impact of task complexity on information use in multi-attribute decision making. Journal of Behavioral Decision Making 6:95-111.

Waller, W. S., B. Shapiro, and G. Sevcik. 1999. Do cost-based pricing biases persist in laboratory markets? Accounting, Organizations and Society 24:717-39.

Windmeijer, F. A. G. 1995. Goodness-of-fit measures in binary choice models. Econometric Reviews 14:101-16.

Wright, G., and P. Ayton. 1988. Immediate and short-term judgmental forecasting: Personoligism, situationism of interactionism? Personality and Individual Differences 9:109-20. 